\title{
Introduction to the Supplement
}

\author{
Jeffrey P. Jacobs \\ The Congenital Heart Institute of Florida, Division of Thoracic and Cardiovascular Surgery, All Children's \\ Hospital/Children's Hospital of Tampa, University of South Florida College of Medicine, Cardiac Surgical \\ Associates, Saint Petersburg and Tampa, Florida, United States of America
}

$T$ His Supplement to Cardiology in the Young represents the fifth annual Supplement generated from the two meetings that compose "Heart Week in Florida". ${ }^{1-4}$ As I have emphasized in previous supplements, Florida is the fourth largest state in the United States of America. The programme for care of children with congenital cardiac malformations at Children's Hospital of Philadelphia is one of the largest, and most prestigious and comprehensive, in the world. The Congenital Heart Institute of Florida, in turn, is the largest and most comprehensive programme providing services for patients with congenital cardiac disease in Florida. "Heart Week in Florida", the joint collaborative project sponsored by the Cardiac Center at the Children's Hospital of Philadelphia, together with the All Children's Hospital of Saint Petersburg and the Congenital Heart Institute of Florida, is now recognized as one of the major planks of continuing medical and nursing education for those working in the fields of diagnosis and treatment of heart disease in neonates, infants, children, and adults.

All institutions involved with the organization of the events of "Heart Week in Florida" are very grateful to Bob Anderson, and the team at Cardiology in the Young, for their support, and for the opportunity to publish this Supplement. By the time many of you read this Supplement, a three day meeting will have been held on Wednesday

Correspondence to: Jeffrey P. Jacobs MD, FACS, FACC, FCCP, Cardiovascular and Thoracic Surgeon, The Congenital Heart Institute of Florida (CHIF), Clinical Associate Professor, University of South Florida (USF), Cardiac Surgical Associates (CSA), 603 Seventh Street South, Suite 450, Saint Petersburg, FL 33701. Tel: +727 822 6666; Cell Phone: +727 235 3100; Fax: +727 821 5994 E-mail: JeffJacobs@msn.com, http://www.heartsurgery-csa.com/, http:// www.CHIF.us/
September 26 through Friday September 282007 at the Institute of Child Health in London, United Kingdom, to mark the retirement of Professor Anderson. ${ }^{5}$ This meeting is titled "The Advance of Knowledge in Cardiac Morphology and Development: Morphology and Music - The Retirement Symposium of Professor Robert Anderson". The meeting reviews the advances made in the understanding of the development and structure of the normal and congenitally malformed heart during the time of Bob Anderson's support by the British Heart Foundation. Musical recitals are scheduled to take place during the lunch breaks on all 3 days, and there is a reception planned for the evening of Thursday, September 27th. With the upcoming retirement of $\mathrm{Bob}$, the remaining Editors of this Supplement would like to dedicate this Supplement to him. Anyone involved in the care of patients with congenitally malformed hearts knows that Bob Anderson is a giant in this field. He is one of the greatest cardiac morphologists ever, and has made academic accomplishments too numerous to list. Bob studied at the University of Manchester from 1960 through 1966. Since 1979, he has been the Joseph P. Levy Professor of Paediatric Cardiac Morphology, supported by the British Heart Foundation. In 1984, Bob was awarded the British Heart Foundation Prize and Gold Medal for Cardiovascular Research. At the time of writing this foreword, Bob had authored 40 theses and books, 259 chapters in edited books by invitation, 654 papers in reviewed journals, 192 invited articles, editorials and letters, 9 electronic publications, and 14 other publications and videotapes. $\mathrm{He}$ is the founding and current editor-in-chief of the leading journal in the world for those who care for patients with congenitally malformed hearts, namely Cardiology in the Young. Not only is he a 


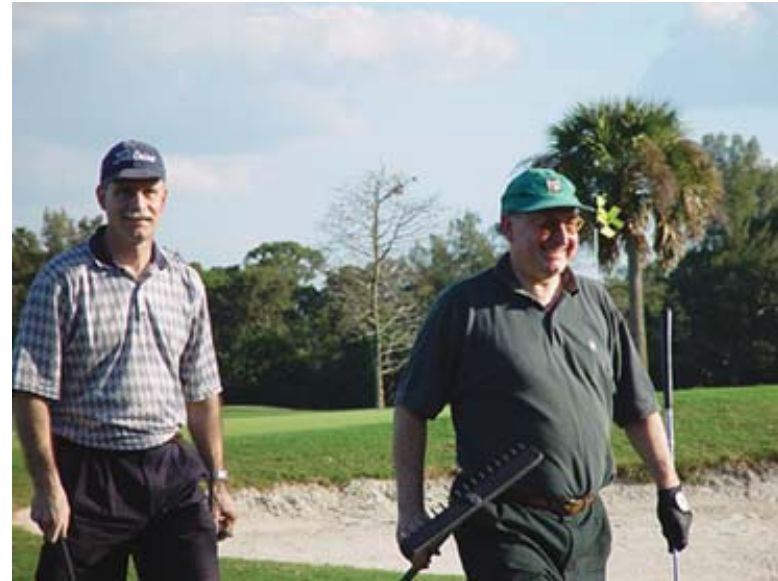

Figure 1.

Bob Anderson hard at work during his daily golf game in Saint Petersburg, Florida. Photo taken Thursday, January 31, 2002.

scientist and academician, he is also a political and administrative leader in our field.

On a personal note, I would like to congratulate Bob on his upcoming retirement, and thank him for his support, friendship, mentorship, professional guidance, and advice over the past 10 years. Bob has played a major role in the development of my own career, and I am appreciative for all that he has done for me. He placed an amazingly high level of trust in me when I was very young, and I appreciate this support. Bob has also been a strong supporter and advocate of our programme at All Children's Hospital and The Congenital Heart Institute of Florida for quite some time. In 2008, Bob will be a featured speaker at our annual February meeting for the seventh consecutive year. Every morning for all seven of these years, we have begun our sessions with an anatomy lesson from Bob. On a daily basis, he sets the stage for the rest of the day, and raises the academic level of our meeting. He has supported our programme in many other ways as well. In 2008, he will spend a day teaching the anatomy of the congenitally malformed heart to our nursing staff. Bob, and his wife Christine, are very well rounded people with many interests. In Florida, we have enjoyed our collaboration with Bob and Christine on many levels beyond the awesome academics:

- Christine and Bob are skilled golfers who take this sport quite seriously, and play golf on more or less a daily basis while in Florida (Fig. 1).

- Bob and Christine have been fishing off the dock in my back yard, and from a boat in Tampa Bay. I am hopeful to play a role in the further development of their fishing skills (Fig. 2).

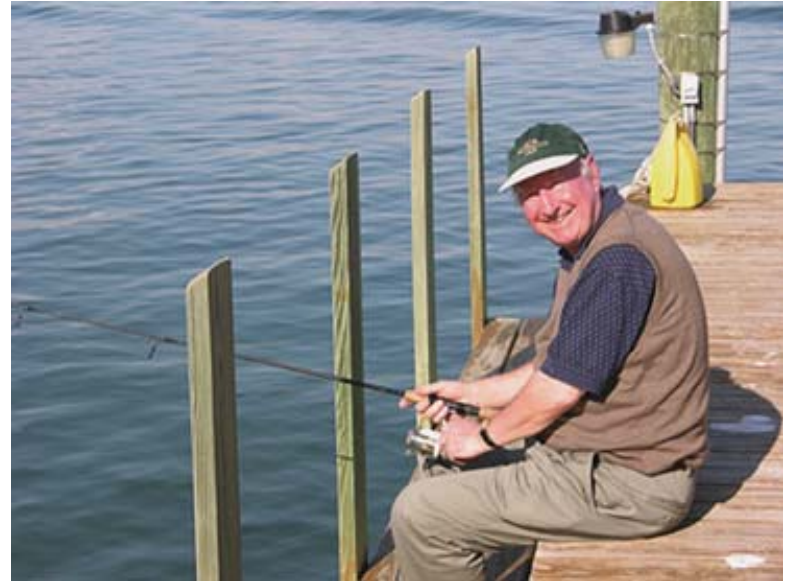

Figure 2.

Bob Anderson fishing in Tampa Bay. Photo taken Thursday, February 16, 2006.

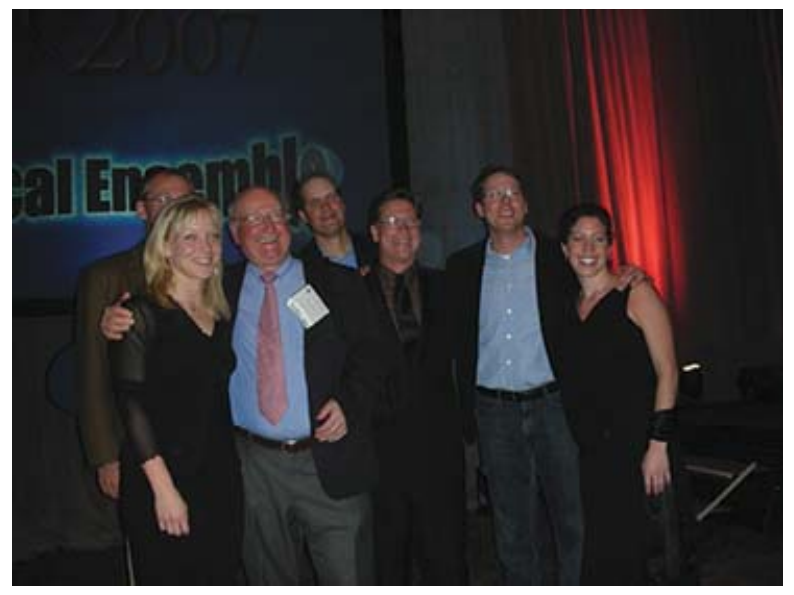

Figure 3 .

Bob Anderson, Gil Wernovsky, and the Cardiology 2007 Musical Ensemble. Photo taken Friday, February 23, 2007.

- Bob is a skilled musician who has entertained us as a pianist many times (Fig. 3).

- Bob and Christine enjoy good food and wine, and they have shared many wonderful evenings with our team (Fig. 4).

My wife Stacy and I consider Bob and his wife Christine great personal friends, and we look forward to many decades more of friendship and collaboration. The Editors of this Supplement are pleased to state that this fifth annual Supplement generated from "Heart Week in Florida" is our best Supplement ever, and we are proud to dedicate this Supplement to Bob and Christine Anderson.

The Cardiac Center at the Children's Hospital of Philadelphia hosted their 10th Annual Postgraduate 


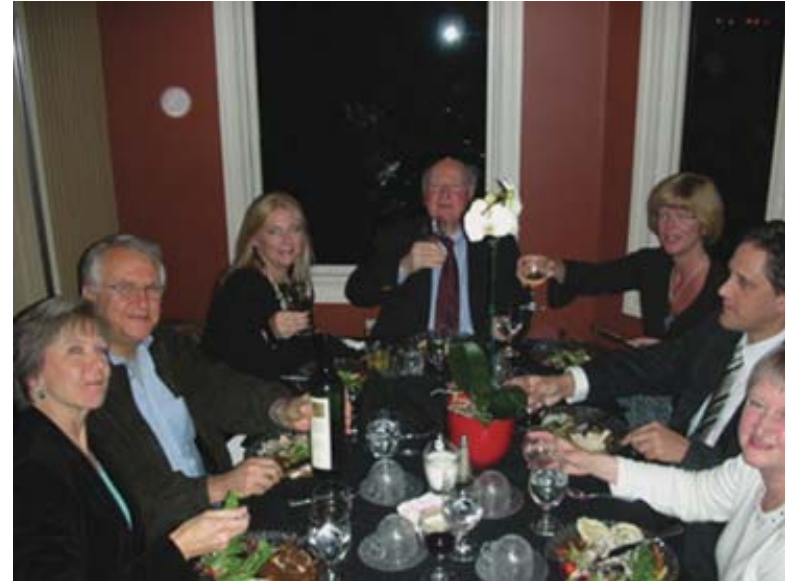

Figure 4.

Bob and Christine Anderson, Norm Silverman, Diane DebichSpicer, Heidi Hess and friends during "Heart Week in Florida". The editors dedicate this Supplement to bonour the retirement of our friend and colleague Bob Anderson. Photo taken Friday, February 16, 2007.

Course at Disney's Yacht and Beach Club Resorts in sunny Orlando, Florida, from February 21st through 25th, 2007. Over 750 professionals and exhibitors gathered from around the globe to hear late-breaking research, to discuss controversial topics, to review current practices, and to enjoy each others' company and insight. ${ }^{6}$ Physicians made up approximately half of the attendees, and included representation from all disciplines involved in the care of children with cardiac disease, including cardiologists, intensivists, surgeons, anaesthesiologist, neonatologists and maternal fetal specialists. Approximately 50 physicians, or "physicians-to be", were fellows, residents or medical students. The remaining attendees included advanced practice, operating room, catheterization lab and bedside nurses, sonographers, physician assistants, respiratory therapists, perfusionists, and administrators. A highlight of the meeting organized by Children's Hospital of Philadelphia is the featured lectures in Cardiology, Cardiac Surgery, and Nursing (Table 1). In 2008, the Cardiac Center at the Children's Hospital of Philadelphia will host their 11th Annual Postgraduate Course in the balmy setting of Scottsdale, Arizona, thanks to the support provided by our colleagues working at Children's Hospital in Phoenix. The general plan for this meeting is to alternate annually between an east coast meting and a west coast meeting. In 2008, therefore, the 11th Annual PostGraduate Course organized by Children's Hospital of Philadelphia will be held in Scottsdale Arizona, from February 6th through 10th, 2008, at the beautiful Hyatt
Table 1. The Featured Lectures given thus far during the Annual Postgraduate Course in Pediatric Cardiovascular Disease organized by Children's Hospital of Philadelphia.

The "C. Walton Lillehei" Lecture
2000

2001

2002

2003

2004

2005

2006

2007

The "William J. Rashkind" Lecture

2002

2003

2004

2005

2006

2007

The “T. Garrett Rauch” Memorial Nursing Lecture

$2000 \quad$ Jane Barnsteiner

2001

2002

2003

2004

2005

2006

2007
Thomas R. Karl

Marc de Leval

Aldo R. Castaneda

Thomas L. Spray

William G. Williams

Edward L. Bove

Martin Elliott

Pedro J. del Nido

Thomas P. Graham Welton M. Gersony Jane W. Newburger Norman H. Silverman Andrew N. Redington Philipp Bonhoeffer

Nancy Eckle Catherine K. Madigan Patricia A. Hickey Mary Fran Hazinski Elisabeth C. Smith Kathleen Mussatto Martha A. Q. Curley
Gainey Ranch and Spa. For detailed information, please e-mail Tina Mannices at: mannices@email. chop.edu

In 2007, the component of the joint programme organized by the Congenital Heart Institute of Florida, along with All Children's Hospital, and representing our own seventh annual International Symposium on Congenital Heart Disease, was held immediately prior to the meeting in Orlando, and was again blessed with wonderful weather, and awesome presentations from the stellar faculty. This programme had 269 Attendees from 14 countries, and 30 different states in the United States of America. Attendees were made up by two-fifths physicians, one-quarter nurses, one-sixth perfusionists, and one-sixth ultrasonographers and allied health professionals. Physician specialties included cardiology, cardiac surgery, cardiac intensivists, cardiac anaesthesiology, and neonatology. In Table 2, I highlight the featured topics and speakers from the meeting held in St Petersburg. The true summit of this meeting is the George Daicoff Lecture, given by the featured speaker to honour the founder of our surgical programme in St. Petersburg. We have now reached the situation whereby the proceedings of the meetings held in 2003, 2004, 2005, and 2006 were published as supplements to Cardiology in the 
Table 2. Featured Topics and Speakers during the Symposiums organized by the Congenital Heart Institute of Florida and All Children's Hospital.

\begin{tabular}{ll} 
2002: & Second Annual Symposium: \\
\hline Focus: & Abnormalities of the Ventricular Inlets and Atrioventricular \\
& Valves \\
Day 1: & Echocardiography \\
Day 2: & Tricuspid valve \\
Day 3: & Mitral valve \\
Day 4: & Common atrioventricular valve \\
Featured Guest Speaker & Bob Anderson, Great Ormond Street, London, United Kingdom \\
2003: & Third Annual Symposium \\
\hline
\end{tabular}

\section{Focus:}

Day 1:

Day 2:

Day 3:

Day 4:

Featured Guest Speakers

2004:

Focus:

Day 1:

Day 2:

Day 3:

Day 4:

Featured Guest Speaker

2005:

Focus:

Day 1:

Day 2:

Day 3:

Day 4:

Featured Guest Speaker

2006:

Focus:

Day 1:

Day 2:

Day 3:

Day 4:

Day 5:

Featured Guest Speakers

2007:

Focus:

Day 1:

Day 2:

Day 3:

Day 4:

Featured Guest Speakers
Hypoplastic Left Heart Syndrome

Echocardiography

Staged palliation and the Norwood operation

Replacement therapy and cardiac transplantation

Biventricular repair

Leonard L. Bailey and his wife Nancy,

Loma Linda University Medical Center, Loma Linda, California

Fourth Annual Symposium

Controversies concerning the Ventriculo-arterial Junctions

Echocardiography

Pulmonary valve and reconstructions of the right ventricular outflow tract

The aortic valve and the Ross procedure

The arterial switch procedure

Martin J. Elliott, Great Ormond Street, London, United

Kingdom

Fifth Annual Symposium

The Functionally Univentricular Heart

Echocardiography

Shunts and bands

Glenn and Fontan procedures

Cardiac transplantation

Marc deLeval, Great Ormond Street, London, United Kingdom

Sixth Annual Symposium

Ventricular Inlets and Atrioventricular Valves

Echocardiography

Tricuspid valve

Mitral valve

Common atrioventricular valve

Discordant atrioventricular connections

Ross M. Ungerleider, and his wife Jamie Dickey, of the

Doernbecher Children's Hospital, Oregon Health Sciences

University, Portland, Oregon

Seventh Annual Symposium

Hypoplastic Left Heart Syndrome

Echocardiography

Staged palliation and the Norwood operation

Replacement therapy with cardiac transplantation, biventricular repair and hybrid procedures

Adults with congenital heart disease

Constantine Mavroudis and Carl Backer, Children's Memorial

Hospital, Chicago, Illinois 


\begin{tabular}{ll}
\hline 2008: & Eighth Annual Symposium \\
\hline Focus: & Tetralogy of Fallot \\
Day 1: & Echocardiography \\
Day 2: & Tetralogy of Fallot with pulmonary stenosis \\
Day 3: & Complex tetralogy of Fallot \\
Day 4: & Adults with congenital heart disease - late problems with TOF \\
& Pediatric cardiac critical care \\
Featured Guest Speaker & Tom Spray Children's Hospital of Philadelphia \\
\hline
\end{tabular}

Young. ${ }^{1-4}$ This supplement is the third that we have produced jointly with Children's Hospital of Philadelphia, our prior joint efforts gathering together the written account of the activities of the meetings held in 2004 and $2006 .^{2,4}$ In 2008, the Congenital Heart Institute of Florida and All Children's Hospital will host our 8th annual meeting, which will take place from February 15 through 19. The focus will be tetralogy of Fallot, with additional symposiums about adults with congenital heart disease, and paediatric cardiac critical care. The featured Daicoff lecture will be given by Tom Spray. For detailed information, please e-mail Melodye Seals at: SealsM@allkids.org

The part of the joint programme organized by the Congenital Heart Institute of Florida and All Children's Hospital will continue to take place in St Petersburg, even in the years when the part designed by Philadelphia will be held on the west coast, as will occur in 2008. Even during these years when the Philadelphia meeting is held outside of Florida, "Heart Week" will continue to be a collaborative project as manifest by the collaborative publication of this Supplement, as well the various shared members of our international faculties. As has been stated on the web site for the programme coordinated by Philadelphia, "Providing optimal care for neonates, children and young adults with heart disease requires a multidisciplinary team approach, including physicians (from cardiology, cardiac surgery, cardiothoracic anesthesia, neonatal and paediatric critical care medicine, and multiple consulting services), nurses, perfusionists, respiratory therapists, social workers and many others. All of these various practitioners must be experts in their own area, but should also be knowledgeable in what the other members of the team provide to the overall care of the patient." This statement presents the rational for not only the annual part of the meeting emanating from Philadelphia, but also for "Heart Week in Florida". Both meetings are proud to emphasize collaboration that spans traditional subspecialty and professional boundaries.
It is gratifying for me, as a representative of the Congenital Heart Institute of Florida, to confirm our ongoing commitment to continue "Heart Week in Florida", combining the International Symposium on Congenital Heart Disease organized by All Children's Hospital and The University of South Florida with the annual postgraduate course in Pediatric Cardiovascular Disease organized by Children's Hospital of Philadelphia. I thank Gil Wernovsky, Director of the meeting organized by Children's Hospital of Philadelphia, as well as Tina Mannices, Manager of Continuing Medical Education at the Children's Hospital of Philadelphia, and also Tom Spray and Bill Gaynor, for their support. In 2007, the two meetings came together again in Florida. The part to be held in St Petersburg took place from February 16 through 20, 2007, and focused on hypoplastic left heart syndrome, with a special one day mini-symposium about adults with congenital heart disease. The tenth update provided by Children's Hospital of Philadelphia was held in Orlando on February 21 through 25, 2007. This meeting once again provided a comprehensive post-graduate course for paediatric cardiologists, neonatologists, surgeons, nurses, intensivists, anaesthesiologists, sonographers, perfusionists. In essence, it provided something for all those involved in the care of neonates and children with cardiovascular disease.

The Supplement that you are now about to read, therefore, focuses on Controversies and Challenges Facing Paediatric Cardiovascular Practitioners and their Patients. It has three sections, which have been prepared so as to give a flavour of the presentations given in Florida in February of 2007. The reviews in the first section discuss the anatomy, along with diagnostic and therapeutic strategies, related to heterotaxy. The first review in this section summarizes the deliberations of the Nomenclature Working Group concerning the relationship between visceral heterotaxy, the splenic syndromes, and isomerism as it can be seen within the body. This manuscript provides consensus definitions for heterotaxy, and a variety of related terms. 
The second review, expertly collated by Meryl Cohen, includes contributions from all those who presented in the closing symposium of the meeting organised by Children's Hospital of Philadelphia, and dedicated to the memory of Stella Van Praagh, discussing heterotaxy. The third review, orchestrated by Andy Atz, is based on data about patients with heterotaxy submitted from the centres in North America that together constitute the Pediatric Heart Network. In the second section of the Supplement titled "Selected Topics in Congenital and Acquired Cardiac Disease and the Current State and Future Directions in Care of Patients, Research, and Teaching”, 8 topics are discussed that are broad in scope. This section includes several multidisciplinary, multi-institutional papers dealing with topics that include coronary arterial disease in children, the patent arterial duct, hypoplastic left heart syndrome, adults with congenital cardiac disease, the cardiac autopsy, extracorporeal membrane oxygenation, cardiopulmonary resuscitation, and patient safety. In the final section of the Supplement, we pay tribute to another of the founding fathers of our profession, George Daicoff. We review several related topics that all fall under the general heading of professionalism. For those charged with the task of caring for patients with congenitally malformed hearts, professional success and happiness require an understanding and appreciation of the topics of professional relationships, personal relationships, mentorship, learning curves, balance, and the analysis of outcomes of treatments for our patients. In this final section, we discuss these topics and present two articles generated from the annual George Daicoff Lecture Series organized by All Children's Hospital and The Congenital Heart Institute of Florida, as well as two closely related articles discussing "Mentorship, Learning Curves, and Balance" and "Analysis of Outcomes for Congenital Cardiac Disease".

Over the years, Heart Week in Florida has provided many opportunities for the excellent scientific exchange of ideas, and the development of awesome friendships. I would like to again thank Bob Anderson for all of his help, support, trust, and patience during the preparation of this Supplement. I would also like to thank my good friends and co-editors of this Supplement, Gil Wernovsky and J. William Gaynor. I am especially grateful to
Jean Francis and Michael Epstein, Vice Presidents of All Children's Hospital, for facilitating the publication of this Supplement. I would also like to thank several additional members of our team at All Children's Hospital, namely Gary Carnes, President and Chief Executive Officer of All Children's Hospital, Joel Momberg, Cindy Rose, Pat Clark, Melodye Seals, Tina Merola, Kas Sheehan, Jean Wilhelm, and all our cardiac nurses. I would also like to thank the other Directors of our St. Petersburg meeting, namely James C. Huhta, Richard Martinez, David Cooper, and my partner James A. Quintessenza. Jim Huhta initiated this meeting, and I am grateful that he gave me the opportunity to work with him. The meeting would not have been possible without his leadership and vision. Finally, I would like to thank my current partners, Jim Quintessenza and Paul Chai, and, and my former partners, Victor Morell and Harald Lindberg, for their constant support and guidance, and my wife Stacy, and children Jessica and Joshua, for their understanding and patience. It continues to be an ongoing fact, as I have emphasized in previous introductions, that all of the family members of the authors of the reviews included in this Supplement are owed a debt of gratitude, because writing manuscripts markedly decreases the time available with them. Unfortunately, even with the passage of time, these periods of writing and editing are showing no signs of disappearance.

\section{References}

1. Jacobs JP, Anderson RH (eds).Controversies Relating To The Hypoplastic Left Heart Syndrome. Cardiol Young 2004; 14 (1 Suppl): 1-130.

2. Jacobs JP, Wernovsky G, Gaynor JW, Anderson RH (eds). Controversies of the Ventriculo-Arterial Junctions and Other Topics. Cardiol Young 2005; 15 (1 Suppl): 1-198.

3. Jacobs JP, Wernovsky G, Gaynor JW, Anderson RH (eds). Controversies and Challenges in the Management of the Functionally Univentricular Heart. Cardiol Young 2006; 16 (1 Suppl): 1-104.

4. Jacobs JP, Wernovsky G, Gaynor JW, Anderson RH (eds). Controversies and Challenges of the Atrioventricular Junctions and Other Challenges Facing Paediatric Cardiovascular Practitioners and their Patients. Cardiol Young 2006; 16 (3 Suppl): $1-156$.

5. http://www.ich.ucl.ac.uk/education/short_courses/courses/2T20/ accessed July 27, 2007.

6. Wernovsky G. Foreword: Cardiology 2007 - 10th Annual Update on Pediatric Cardiovascular Disease. Cardiol Young 2007; 17 (1 E-Suppl): 1-9. 